\title{
Approaches to Suppressing Shaft Voltage in Non-Insulated Rotor Brushless DC Motor driven by PWM Inverter
}

\author{
Yoshinori Isomura*, Kichiro Yamamoto**, Shigeo Morimoto*** \\ Tatsuo Maetani*, Akihiko Watanabe* and Keisaku Nakano*
}

\begin{abstract}
The voltage source PWM inverter generally used to drive the air conditioning (A/C) fans has been posing a large issue that the bearings in air conditioning fan motors are highly possible to be corroded electrically. Potential difference called shaft voltage is generated between inner and outer rings of the bearings due to inverter switching. The shaft voltage causes bearing lubricant breakdown dielectrically. As a result, bearing current is caused. This current causes the bearing corrosion. In previous work, we demonstrated that the shaft voltage can be reduced by using an insulator inserted between the outer and inner cores of the rotor in an air conditioning fan motor without grounding. This paper proposes the other countermeasure for reducing the shaft voltage in fan motors. The countermeasure which adds a capacitor between the brackets and the stator core is effective even for fan motors with non-insulated rotor. The effectiveness is confirmed by both simulated and experimental results.
\end{abstract}

Keywords: Shaft Voltage, Bearing, Common-mode Voltage

\section{Introduction}

As the need for energy-saving measures increases, the number of brushless DC motors used to drive airconditioning fans have been rapidly increasing. And voltage-source pulse-width modulation (PWM) inverters generally used to drive the fan motors have been posing a major problem. The problem is a high probability of the electrical erosion of bearing in the motors. A potential difference, called the shaft voltage, is generated between the outer and inner races by inverter switching, and this voltage causes the dielectric breakdown of the bearing lubricant. The current produced by the dielectric breakdown, also called "electric discharge machining (EDM) current", results in a current passing through the bearing and causes electrical erosion in the bearing [1]-[14].

The shaft voltage can be suppressed by suppressing either the common-mode voltage causing shaft voltage or

* Motor Business Division, Appliances Company, Panasonic Corporation, Japan. (isomura.yoshinori@jp.panasonic.com; maetani.tatsuo@panasonic.com;

watanabe.aw@jp.panasonic.com;

nakano.keisaku@jp.panasonic.com)

** Dept. of Electrical and Electronics Engineering, Kagoshima University, Japan .(yamamoto@eee.kagoshima-u.ac.jp)

*** Dept. of Electrical and Information Systems, Graduate School of Engineering, Osaka Prefecture University, Japan. (morimoto@eis.osakafu-u.ac.jp)

Received 27 December 2013; Accepted 11 Feb 2014 the shaft voltage itself. Previously, we proposed an insulated rotor which can suppress the shaft voltage in brushless DC motors for air conditioning [6],[13],[14].

However, the subject that new equipment was required for an insulated rotor occurred.

In this paper, we report on suppressing shaft voltage by addition of a capacitor to the non-insulated rotor brushless DC motor driven by PWM inverter. First, shaft voltage is simulated from the equivalent circuit and it is confirmed that the simulated shaft voltage has good agreement with a measurement result. Next, the structure, which is added a capacitor between the brackets and the stator core, is presented. And also the optimal placement of the capacitor is investigated by simulation of shaft voltage.

\section{Shaft Voltage Reduction with the Non-Insulated Rotor}

\subsection{Common-mode Equivalent Circuit of Ungrounded Motor}

Fig. 1 shows the external view of a concentrated winding brushless DC motor used to drive an air conditioning fan. This motor is a surface permanent magnet synchronous motor in which the stator core and stator windings are molded with resin and a ferrite plastic magnet is also 
molded on the rotor core surface. Metal brackets are mounted on the top and bottom of the stator to hold the earing. Both metal brackets are connected each other inside the motor. The inverter circuit to drive the motor is mounted on the stator of the motor. The rated output power of the motor is $60 \mathrm{~W}$, and the inverter operates under twophase modulation. Two 608 type bearings are used and each are lubricated by a ureabased lubricant with a base-oil viscosity of $53 \mathrm{~mm} 2 / \mathrm{s}$.

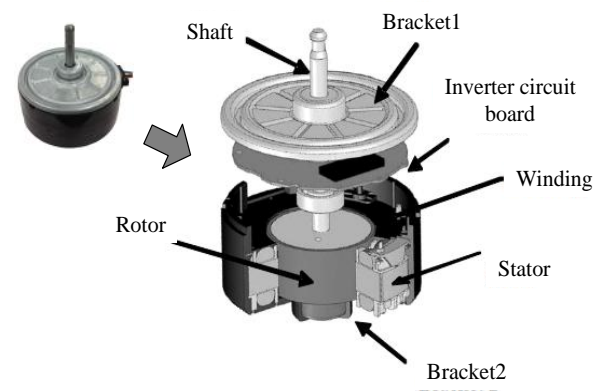

Fig. 1. Brushless DC motor

Fig. 2 shows the capacitive coupling in the brushless DC motor. The shaft voltage of the motor vsh is the voltage between shaft and brackets and is also the voltage across bearing capacitances $\mathrm{Cb} 1$ and $\mathrm{Cb} 2$. And the electric potential of the shaft is decided by voltage division of shaft side capacitances $\mathrm{Cs}, \mathrm{Cg}, \mathrm{Cmg}, \mathrm{Cm}$ and $\mathrm{Csn}$, and the potential of the bracket is decided by voltage division of bracket side $\mathrm{Csb}$ and $\mathrm{Cn}$. Based on the bridge equivalent circuit in Fig. 3, the motor was disassembled into each component such as stator and rotor, and capacitances were measured for each respective part exclusively or in combination.

Fig. 3 shows an ungrounded 3-phase common-mode equivalent circuit. Table I lists measured capacitances from parts of the motor for the equivalent circuit [6]. In previous paper [6], we proposed an equivalent circuit for the insulated rotor brushless DC motor. The equivalent circuit has a bridge-type structure, and was developed with consideration of the following fact:

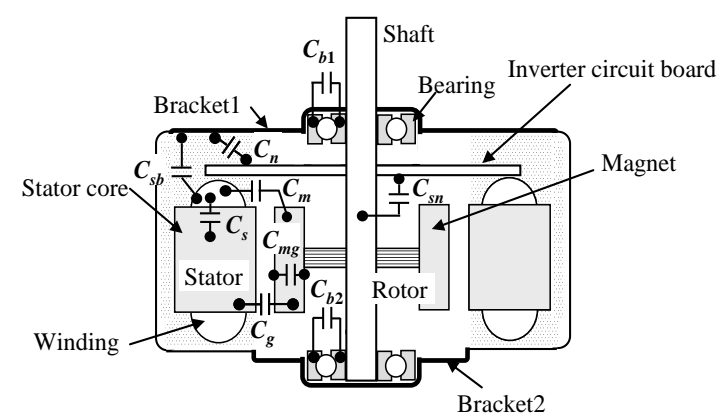

Fig. 2. Motor capacitive coupling
- The shaft voltage varies depending on the capacitance value of the insulated rotor, and

- The polarities of both common-mode and shaft voltages become reverse when the capacitance of the insulated rotor diminishes.

In Fig. 3, we use the equivalent circuit for the ungrounded motor by removing a capacitor for the insulated rotor.

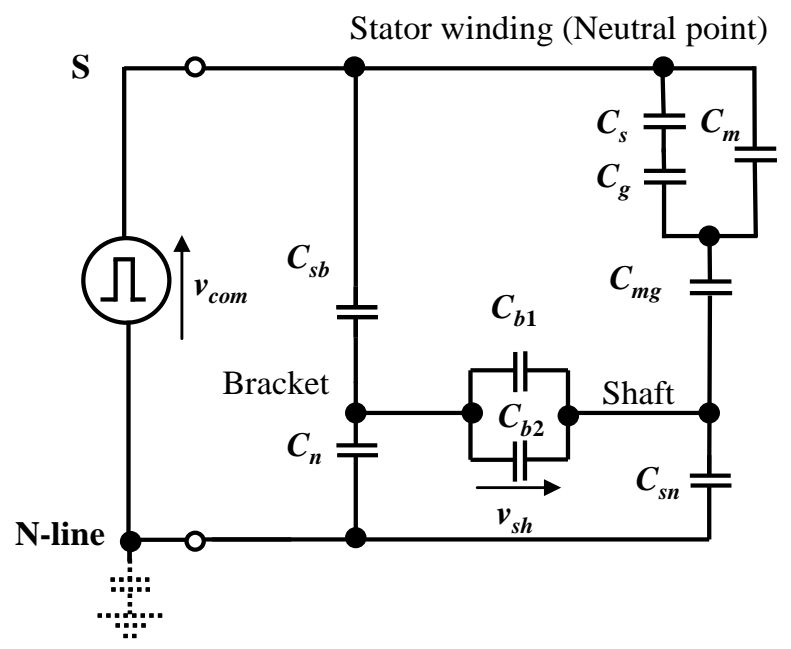

Fig. 3. Bridge-type equivalent circuit of the motor common-mode (ungrounded and non-isulated motor)

Table 1. Measured Capacitance in Each Part of Motor

\begin{tabular}{|c|l|c|}
\hline Symbol & \multicolumn{1}{|c|}{ Parameter } & $\begin{array}{c}\text { Measured } \\
\text { value }\end{array}$ \\
\hline$C_{s}$ & Stray capacitance; winding to stator core & $400 \mathrm{pF}$ \\
\hline$C_{g}$ & Stray capacitance; stator core to magnet & $70 \mathrm{pF}$ \\
\hline$C_{m g}$ & Magnet capacitance & $69 \mathrm{pF}$ \\
\hline$C_{m}$ & Stray capacitance; winding to magnet & $8 \mathrm{pF}$ \\
\hline$C_{b}$ & Bearing capacitance $\left(C_{b 1}+C_{b 2}\right)$ & $100 \mathrm{pF}$ \\
\hline$C_{s b}$ & Stray capacitance; winding to bracket & $19 \mathrm{pF}$ \\
\hline$C_{s n}$ & Stray capacitance; shaft to N-line & $7.7 \mathrm{pF}$ \\
\hline$C_{n}$ & Stray capacitance; bracket to N-line & $20 \mathrm{pF}$ \\
\hline
\end{tabular}

The shaft voltage $\mathrm{v}_{\mathrm{sh}}$ is generated between the outer and inner races by inverter switching, because common-mode voltage $\mathrm{v}_{\text {com }}$, which is the voltage between a neutral point $S$ of the inverter output voltage and negative potential $\mathrm{N}$ of the DC link, is divided by capacitances inside the motor.

The measurement results are shown in Table 1 [6]. LCR meter ZM2353 manufactured by NF Corporation was used for the measurements and the measurement frequency was $20 \mathrm{kHz}$ (carrier frequency of the inverter).

- Combined capacitance between the winding and the stator core, Cs: Electrostatic capacity between the neutral 
point of the stator windings and the stator core was measured.

- Electrostatic capacity between the stator core and the magnet, $\mathrm{Cg}$ : The rotor was inserted in the un-wound stator, electrostatic capacity of the stator core and the magnet surface were measured.

- Magnet capacitance, Cmg: The electrostatic capacity between the rotor surface and the shaft was measured.

- Combined capacitance between the $\mathrm{N}$ electric potential and the bracket, $\mathrm{Cn}$ : The bracket and the inverter circuit were inserted in the molded stator only, and the electrostatic capacity between the bracket and inverter was measured.

- Bearing capacitance, Cb1, Cb2: Electrostatic capacities of bearings $608 \mathrm{ZZ}$ at $1000 \mathrm{~min}-1$.

- Combined capacitance between the winding and the magnet, $\mathrm{Cm}$ : The rotor was inserted in the stator, and electrostatic capacity between the neutral point and the shaft was measured as the combined capacitance of $\mathrm{Cm}, \mathrm{Cg}$ and $\mathrm{Cmg}$, and $\mathrm{Cm}$ was calculated.

- Combined capacitance between the $\mathrm{N}$ electric potential and the bracket, $\mathrm{Cn}$ : The bracket and the inverter circuit were inserted in the molded stator only, and the electrostatic capacity between the bracket and the inverter was measured.

Fig. 4 shows the simulation results of common-mode voltage vcom and shaft voltage vsh of the motor. The DC link voltage was $280 \mathrm{~V}$, the motor rotating speed was 1000 min-1, and the motor was operated with no-load.

From the figure, the peak to peak value of the shaft voltage vsh is $10 \mathrm{~V}$.

Specifications of air-conditioning motor are listed in Table 2.

Table 2. Specification of air-conditioning motor

\begin{tabular}{|l|c|c|}
\hline Components & Item (Unit) & Value \\
\hline \multirow{4}{*}{ Motor } & Input voltage $\left(\mathrm{V}_{\mathrm{dc}}\right)$ & $200-391$ \\
\cline { 2 - 3 } & Maximum out put power $(\mathrm{W})$ & 60 \\
\cline { 2 - 3 } & Rated rotation speed $\left(\mathrm{min}^{-1}\right)$ & 1,000 \\
\cline { 2 - 3 } & Rated torque $(\mathrm{N}-\mathrm{m})$ & 0.3 \\
\cline { 2 - 3 } & No. of pole & 8 \\
\cline { 2 - 3 } & No. of slot & 12 \\
\cline { 2 - 3 } & Rotor diameter $(\mathrm{mm})$ & 50.3 \\
\cline { 2 - 3 } & Magnet length $(\mathrm{mm})$ & 24 \\
\cline { 2 - 3 } & Stator outer diameter $(\mathrm{mm})$ & 87 \\
\cline { 2 - 3 } & Stator inner diameter $(\mathrm{mm})$ & 50.9 \\
\cline { 2 - 3 } Inverter & Stack length $(\mathrm{mm})$ & 13 \\
\cline { 2 - 3 } & Switching frequency $(\mathrm{kHz})$ & 20 \\
\hline \multirow{4}{*}{$\begin{array}{l}\text { Grease } \\
\text { (Type 608) }\end{array}$} & modulation method & two-phase \\
\cline { 2 - 3 } & Kinematic viscosity $\left[\mathrm{m}^{2} / \mathrm{s}\right]\left(\mathrm{at} 40^{\circ} \mathrm{C}\right)$ & 53 \\
\cline { 2 - 3 } & Outer diameter & 22 \\
\cline { 2 - 3 } & Inner diameter & 8 \\
\hline
\end{tabular}

\subsection{Shaft Voltage Measurement of ungrounded Motor}

Fig. 5 shows the measurement results of common-mode voltage $v_{\text {com }}$ and shaft voltage $v_{\mathrm{sh}}$ of the motor. The conditions of the measurement were made into the same conditions as the simulation.

From the figure, the bearing lubricant is dielectrically broken down at the peak to peak value of the shaft voltage vsh is $10 \mathrm{~V}$. The results of the simulated value and the measured value were mostly in agreement.

\section{New Further Reduction Method of the Shaft Voltage}

\subsection{Common-mode Equivalent Circuit of New Method}

We examined places to add a capacitor $\mathrm{C}_{\mathrm{adj}}$ (adjusting capacitor) by the equivalent circuit. The places that can be added the capacitor is $\mathrm{N}$-line of the inverter, the brackets and the stator core, there are three ways to connect the capacitor and they are as follows:

-Between the brackets and the stator core

-Between the $\mathrm{N}$-line of the inverter and the brackets

-Between the $\mathrm{N}$-line of the inverter and the stator core
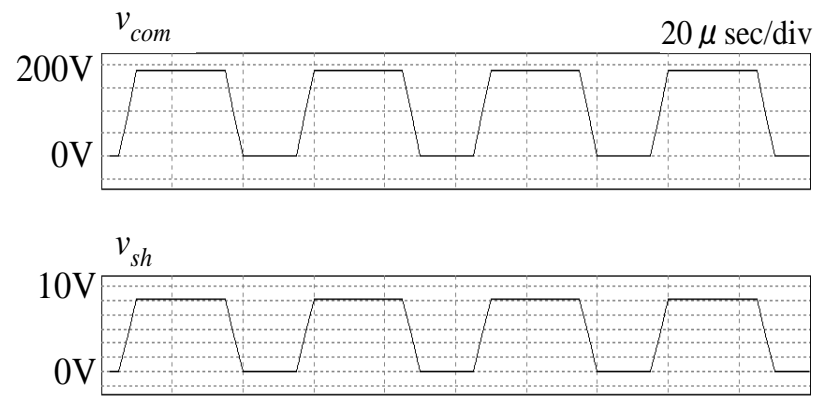

Fig. 4. Simulated common-mode voltage $v_{\text {com }}$ and shaft Voltage $v_{t h}$

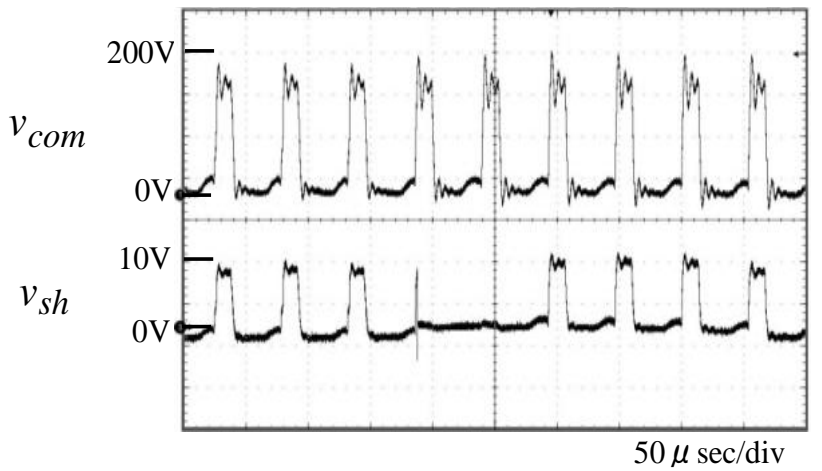

Fig. 5. Measured common-mode voltage $v_{\text {com }}$ and shaft voltage $\mathrm{v}_{\mathrm{sh}}$ (ungrounded and non-insulated motor) 
Fig. 6 shows an equivalent circuit with the adjusting capacitor $C_{a d j}$ between the brackets and the stator core. Fig. 7 shows a simulation result of the shaft voltage when the value of $C_{a d j}$ is changed. Fig. 8 shows the simulation result of the shaft voltage when the value of $C_{a d j}$ is $75 \mathrm{pF}$. From the figure, we can find that the value of $v_{s h}$ is $0.1 \mathrm{~V}$, the polarity of $v_{s h}$ is opposite to that of $v_{c o m}$.

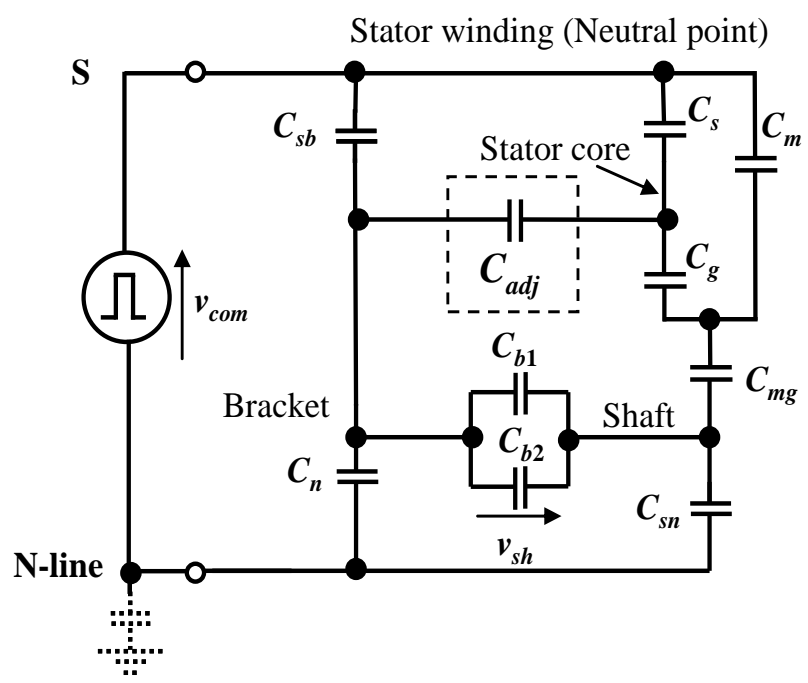

Fig. 6. Equivalent circuit with adjusting capacitor $C_{a d j}$ between the brackets and the stator core

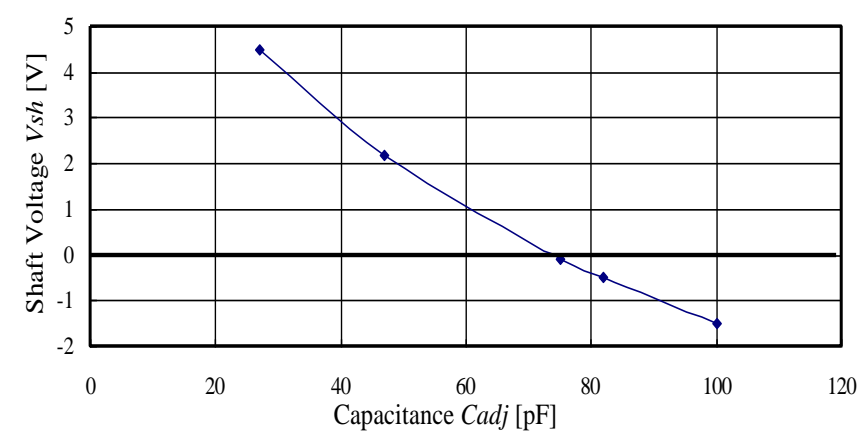

Fig. 7. Simulated shaft voltage $v_{s h}$ when $C_{a d j}$ is changed ( $C_{a d j}$ is between the brackets and the stator core)
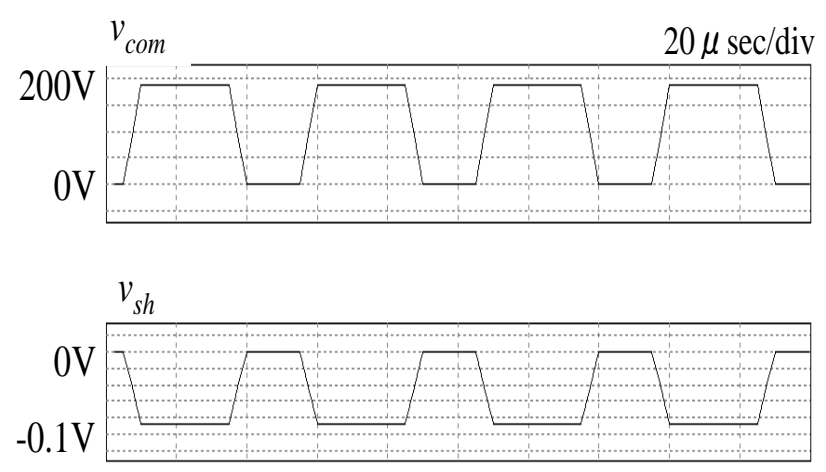

Fig. 8. Simulated shaft voltage $v_{s h}\left(C_{a d j}=75 \mathrm{pF}\right)$
Fig. 9 shows an equivalent circuit with an adjusting capacitor between the $\mathrm{N}$-line and the brackets. Fig. 10 shows a simulation result of the shaft voltage when the value of $C_{a d j}$ is changed. Fig.11 shows a simulation result of the shaft voltage $v_{s h}$ when the value of $C_{a d j}$ is $10 \mathrm{pF}$ and the peak to peak value of $v_{s h}$ is $10 \mathrm{~V}$, the polarity of $v_{s h}$ is same to that of $v_{\text {com }}$.

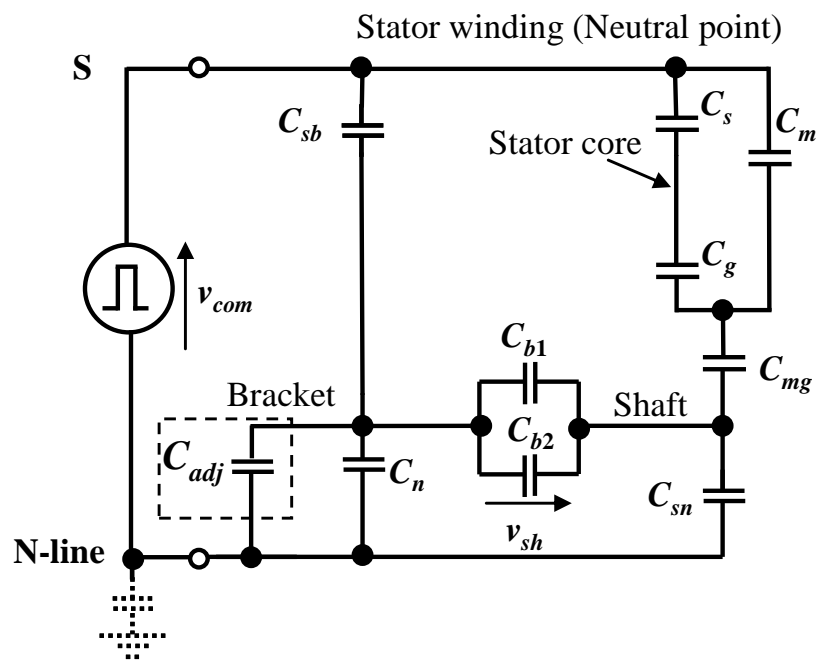

Fig. 9. Equivalent circuit with adjusting capacitor $C_{a d j}$ between the $\mathrm{N}$-line and the brackets

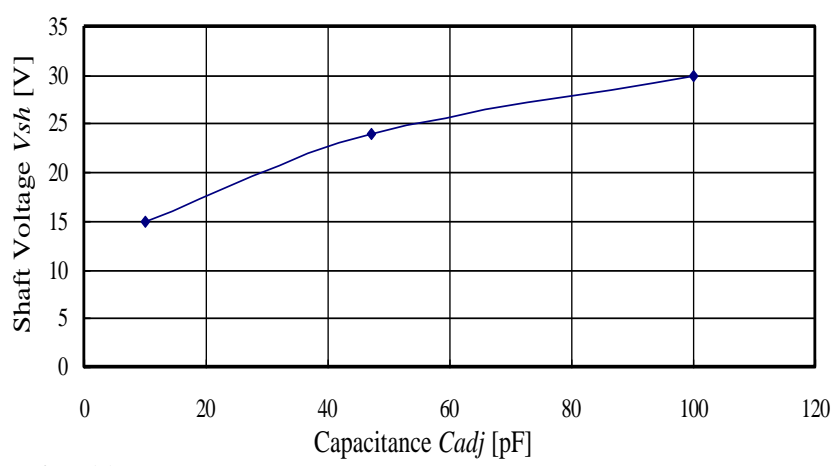

Fig. 10. Simulated shaft voltage $v_{s h}$ when $C_{a d j}$ is changed ( $C_{a d j}$ is between the $\mathrm{N}$-line and the brackets)
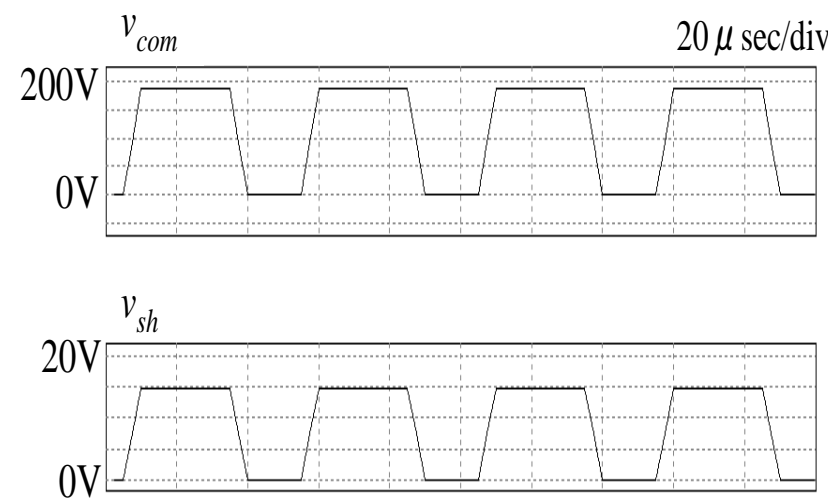

Fig. 11. Simulated shaft voltage $v_{s h}\left(C_{a d j}=10 \mathrm{pF}\right)$ 
Fig. 12 shows an equivalent circuit with an additional capacitor between the N-line and the stator core. Fig. 13 shows a simulation result of the shaft voltage when the value of $C_{a d j}$ is changed. Fig .14 shows a simulation result of the shaft voltage when the value of $C_{a d j}$ is $330 \mathrm{pF}$ and the peak to peak value of $v_{s h}$ is $0.1 \mathrm{~V}$, the polarity of $v_{s h}$ is same to that of $v_{\text {com }}$

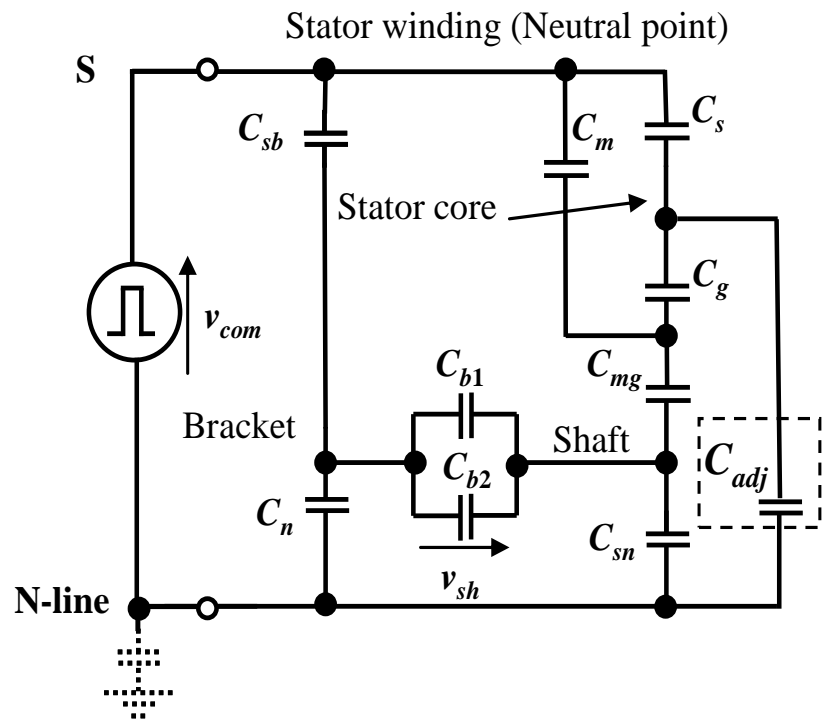

Fig. 12. Equivalent circuit with adjusting capacitor $C_{a d j}$ between the $\mathrm{N}$-line and the stator core

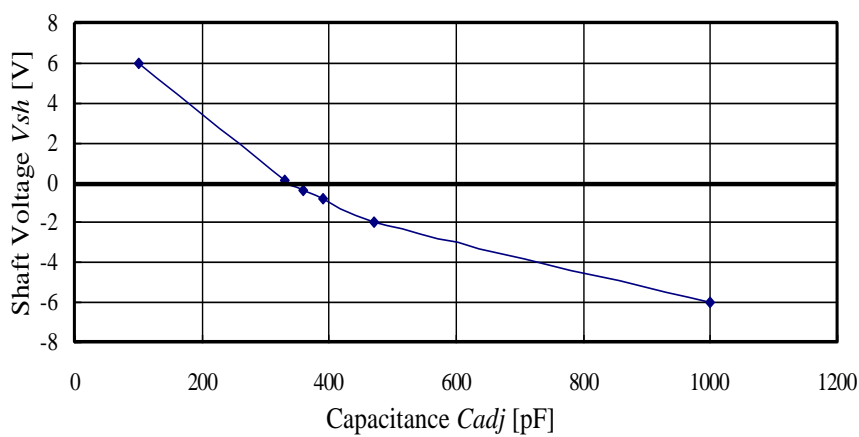

Fig. 13. Simulated shaft voltage $v_{s h}$ when $C_{a d j}$ is changed ( $C_{a d j}$ is between the $\mathrm{N}$-line and the stator core)
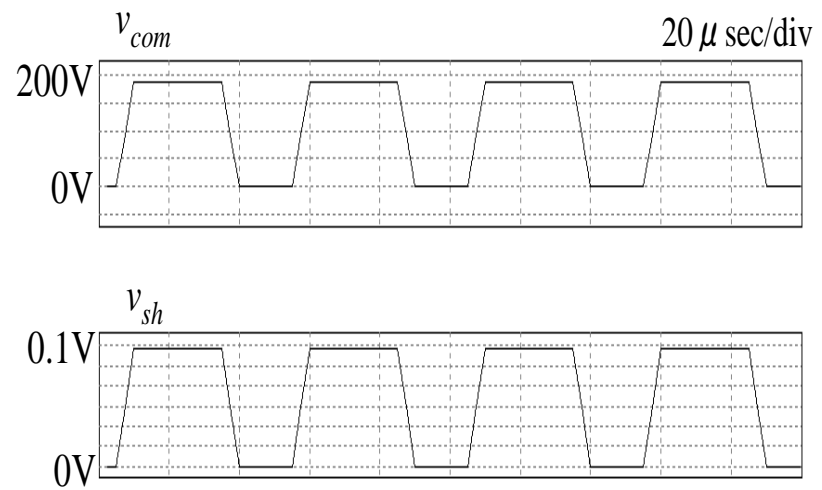

Fig. 14. Simulated shaft voltage $v_{s h}\left(C_{a d j}=330 \mathrm{pF}\right)$
From Figs. 6-14, it is found that putting the adjusting capacitor both between the N-line and the stator core or between the brackets and the stator core are effective to reduce the shaft voltage.

Fig. 15 shows the capacitive coupling in the brushless DC motor which was added an adjusting capacitor $C_{a d j}$ between the brackets and the stator core. To confirm the simulated results, an experiment for the structure in Fig. 15 was done and it is described in the next section.

\subsection{Shaft Voltage Measurement of New Method}

We propose adding the adjusting capacitor $C_{a d j}$ which is a commercial part. The capacitor $C_{a d j}$ is placed between the brackets and the stator core to enlarge the margin by bringing the shaft voltage close to $0 \mathrm{~V}$ from over $10 \mathrm{~V}$.

Fig. 16 shows the measured waveform of shaft voltage with a capacitance $C_{a d j}(=75 \mathrm{pF})$, at the peak to peak value of the shaft voltage $v_{s h}, 0.2 \mathrm{~V}$.

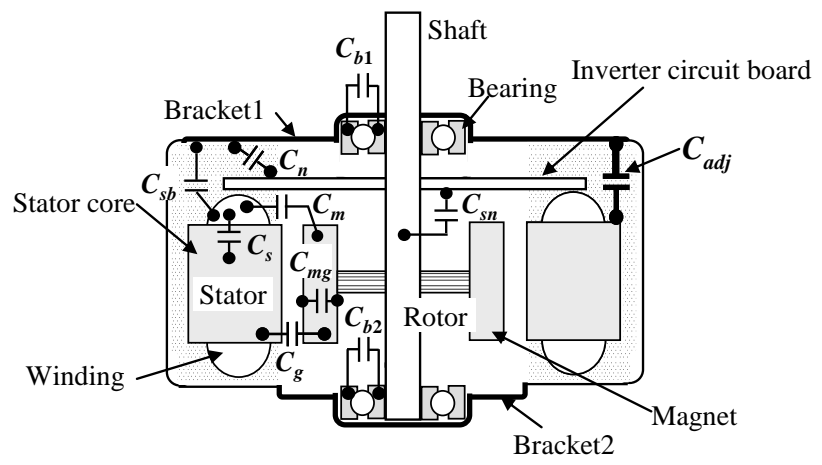

Fig. 15. Motor capacitive coupling for proposed new method

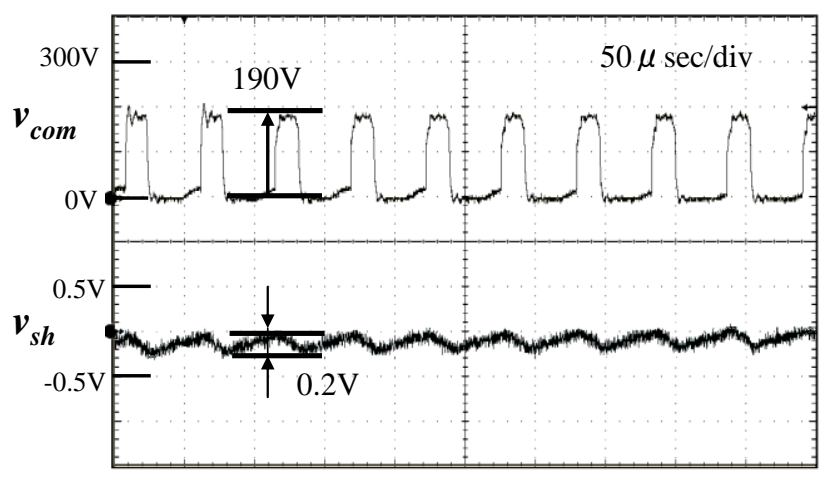

Fig. 16. Measured common-mode voltage $v_{\text {com }}$ and shaft voltage

\section{Conclusion}

For non-insulated rotor brushless DC motor driven by 
PWM inverter, placements of an adjusting capacitor were investigated to reduce the shaft voltage by simulation using simple common-mode equivalent circuit. Three kinds of placements (between the brackets and the stator core, between the $\mathrm{N}$-line of the inverter and the brackets and between the $\mathrm{N}$-line of the inverter and the stator core) were investigated and it was clarified that the placements both between the brackets and the stator core and between the $\mathrm{N}$ line and the stator core are effective for reduction of the shaft voltage.

Based on the simulated results, the new method putting an adjusting capacitor $C_{a d j}$ between the brackets and the stator core was proposed to reduce the shaft voltage in the molded brushless DC motor, and its effectiveness was verified by calculation of simplified equivalent circuit.

Additionally, the other new method putting an adjusting capacitor $C_{a d j}$ between the stator core and the N-line was proposed, and its effectiveness was also verified by calculation of simplified equivalent circuit.

For the former method, the effectiveness was checked by the experimental results which show the reduction of peak to peak value of shaft voltage $v_{s h}$.

We would like to apply this examination result to other types of brushless motors.

\section{References}

[1] S. Chen, T. A. Lipo, and D. Fitzgerald, "Modeling of Motor Bearing Currents in PWM Inverter Drives.," IEEE Trans. Ind. Appl., Vol. 32, No. 6, pp. 1365-1370 (1996-11/12)

[2] D. F. Busse, M. E. Erdman, R. J. Kerkman, D. W. Schlegel, and G. L. Skibinski, "An Evaluation of the Electrostatic Shielded Induction Motor, A Solution for Rotor Shaft Voltage Buildup and Bearing Current," IEEE Trans. IA, Vol. 33, No. 6, pp. 1563-1570 (1997-6)

[3] S. Ogasawara, H. Ayano, and H. Akagi, "Active Cancellation of the Common-mode Voltage Produced by a Voltage-Source PWM Inverter," IEE-Japan Trans. IA, Vol. 117-D, No. 5, pp. 565-571 (1998-5)

[4] K. Yamada, H. Kirino, M. M. Swamy, and T. Kume, "Common-mode Current Attenuation Techniques for Use with PWM Drives," Proc. of the 1999 Japan Industrial Application Society Conference, Vol. III, pp. 75-78 (1999)

[5] K. Iimori, K. Shinohara, K. Yamamoto and A. Morigami, "Approaches to Suppressing Shaft Voltage in Brushless DC Motor Driven by PWM Inverter," IEE-Japan Trans. IA, Vol. 127-D, No. 4, pp. 406-411 (2007-4)

[6] T. Maetani, S. Morimoto, K. Iimori, Y. Isomura and A. Watanabe, "Approaches to Suppressing Shaft Voltage in Brushless DC Motor Driven by PWM Inverter," ICEMS 2011 Beijing, Aug. 20-23, PS-PMM-53 (2011)

[7] K. Tagami, S. Ogasawara, H. Funato, H. Kanazawa, M. Uesugi, and K. Moizumi, "Analysis of Shaft Voltage and Bearing Current in an Inverter-Fed Nongrounded Motor," IEE-Japan Trans. IA, Vol. 127-D, No. 3, pp. 286-292 (20073)

[8] A. Muetze and A. Binder, "Calculation of Motor Capacitances for Prediction of the Voltage Across the Bearings in Machines of Inverter-Based Drive Systems," IEEE Trans. IA, Vol. 43, No. 3, pp. 665-672 (2007-5/6)
[9] R. Naik, T. A. Nondahl, M. J. Melfi and R. Schiferl, "Circuit model for shaft voltage prediction in induction motors fed by PWM-based AC drives," IEEE Trans. Industry Applications, vol. 39, no. 5, pp. 1294-1299 (2003-9/10).

[10] O.Magdum, Y. Gemeinder, and A. Binder, "Investigation of influence of bearing load and bearing temperature on EDM bearing currents," ECCE 2010, Atlanta, pp. 2733-2738, (2010-9).

[11] A. Muetze and A. Binder, "Calculation of Circulating Bearing Currents in Machines of Inverter-Based Drive Systems," IEEE Industrial Electronics, vol. 54, no.2, pp. 932938, (2007).

[12] A. Muetze, J. Tamminen, and J. Ahola, "Influence of Motor Operating Parameters on Discharge Bearing Current Activity," IEEE Trans. IA, Vol. 47, No. 4, pp. 1767-1777 (20119-7/8)

[13] T. Maetani, S. Morimoto, K. Yamamoto, Y. Isomura and A. Watanabe, "Influence of motor rotating speed on shaft voltage of brushless DC motor with insulated rotor driven by PWM Inverters," SPEEDAM 2012, Sorrento, June. 20-22, EMD0012 (2011)

[14] Y. Isomura, K. Yamamoto, S. Morimoto, T. Maetani, A. Watanabe and K Nakano, "Study of the Further Reduction of Shaft Voltage of Brushless DC Motor with Insulated Rotor driven by PWM Inverters," PEDS 2013, Kitakyushu, April. 23-25, pp1184-1189 (2013)

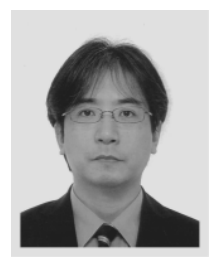

Yoshinori Isomura received the $\mathrm{B}, \mathrm{E}$ in control engineering from Kyushu Institute of Technology, Fukuoka, Japan, in 1992. Since 1992, he been an engineer at Matsushita Electric Industrial Co,.Ltd. Currently, mainly his research and development is the motor control technologies at Panasonic Corporation.

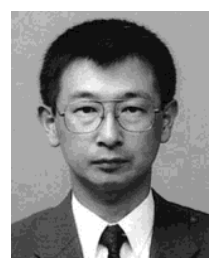

Kichiro Yamamoto received the B. E. and M. E. degrees from Kagoshima University, Kagoshima, Japan, and the Ph.D. degree from Kyushu University, Fukuoka, Japan, in 1987, 1989, and 1996, respectively. He was a Research Associate at Kagoshima National College of Technology, Kagoshima, from 1989 to 1993. Since 1993, he has been with the Department of Electrical and Electronics Engineering, Kagoshima University, where he is currently an Associate Professor. His research interests are ac motor drives and power converter circuits. Dr. Yamamoto is a member of the Institute of Electrical Engineers of Japan. 


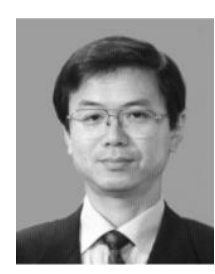

Shigeo Morimoto received the B.E., M.E., and $\mathrm{Ph} . \mathrm{D}$. degrees from Osaka Prefecture University, Sakai, Japan, in 1982, 1984, and 1990, respectively. He joined Mitsubishi Electric Corporation, Tokyo, Japan, in 1984. Since 1988, he has been with the Graduate School of Engineering, Osaka Prefecture University, where he is currently a Professor. His main areas of research interest are permanent magnet synchronous machines, reluctance machines, and their control systems. Dr. Morimoto is a member of the Institute of Electrical Engineers of Japan, the Society of Instrument and Control Engineers of Japan, the Institute of Systems, Control and Information Engineers, and the Japan Institute of Power Electronics.

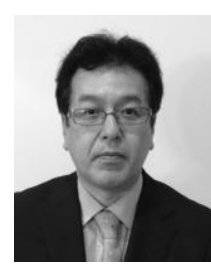

Tatsuo Maetani received the B,E., and $\mathrm{Ph} . \mathrm{D}$. degrees from Osaka Prefecture University, Sakai, Japan, in 1984. Since 1984, he been an engineer at Matsushita Electric Industrial Co,. Ltd. Currently, mainly his reserch and development is the motor control technologies at Panasonic Corporation.

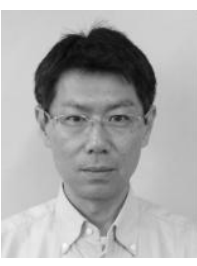

Akihiko Watanabe received the B,E in polymer engineering from Fukui University, Fukui, Japan, in 1989. Since1989, he has been an engineer at the Takefu Matsushita Electric Co,. Ltd. Currently, mainly his research and development is the motor component technologies at Panasonic Motor Expert Co.,Ltd.

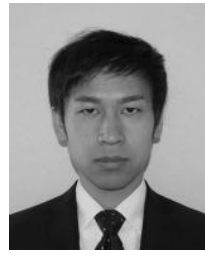

Keisaku akano received the M. E. degrees from Osaka University, Toyonaka, Japan, in 2003. Since 2008, he has been an engineer at Panasonic Corporation. Currently, mainly his research and development is tribology and highperformance materials for motors at Panasonic Corporation. 